\title{
A NOTE ON TEXTS
}

\section{poptoptopto}

I break passages in Pound's verse thus: [ . . ]; but in all other quotations by ellipses without brackets. In the notes, many titles of works are given in abbreviated form, and works by Pound are always cited without the author's name. Full information on all books and articles will be found in the Bibliography. Cross-references to the main text are in the style of the following example: 'see Chapter 5 , text before $n$. 12' (meaning the part of the text in Chapter 5 immediately preceding note-marker 12 ).

In Chapter 4, nn. $14 \mathrm{ff}$, the reader will find a discussion of some textual sources of Pound's Provençal material; also see Introduction, n. 17. Elsewhere, I quote from and refer to the best recent text of any Provencal material, except where the text Pound used (if it is ascertainable) either may throw light on the origin of some point that matters in his product or significantly fails to account for such a point. Translations, from whatever language, are mine unless otherwise indicated; they are intended as literal cribs, even keeping where possible to the line-breaks of the original verse to help future students of Provencal, except in certain instances that are clearly indicated. As there is no canonical spelling of Provencal names, I have not laboured for consistency in this particular, but have taken care that no confusions are possible.

For Pound's own works, I cite the original publication in the case of certain important pieces or where the original text may illuminate the matter in hand. In these cases I often cite in parentheses a currently available publication, if there is one, but I do not use its text unless otherwise stated. For all other Pound material I cite a currently available text. However, individual short poems are cited without source. The source is always the Selected Poems, edited by Eliot, in the edition of 1959 , except for the following, which are quoted according to the text of first publication: 
xiv

'Dompna pois de me no'us cal' (originally $A$ Translation from the Provençal of En Bertrans de Born)

Near Perigord

and the following, which are quoted according to the text given in Collected Early Poems, edited by King:

\author{
In Durance \\ Na Audiart \\ Sestina: Altaforte \\ The Alchemist \\ Guillaume de Lorris Belated: A Vision of Italy \\ Planh for the Young English King \\ Piere Vidal Old \\ Donzella Beata
}

Cantos are cited in the manner devised by Hugh Kenner for The Pound Era, thus: Cantos, 20/89:93 = Canto XX, which is on p. 89 of the 'Revised Collected' edition (Cantos 1-117), published by Faber \& Faber in 1975 (pagination as New Directions, 1970), and p. 93 of the 'New Collected' edition (Cantos 1-109), published by Faber \& Faber in 1964. For Cantos not included in this latter edition, I refer to the 'Revised Collected' and the Faber Drafts and Fragments, thus: Cantos, 110/777:7. Where there are differences, citations are always according to the Faber text. 